\title{
3-Nitrotyrosine in the proteins of human plasma determined by an ELISA method
}

\author{
Jamshad KHAN*, David M. BRENNAN $\uparrow$, Nicholas BRADLEY*, Beirong GA0*, Richard BRUCKDORFER + , and Michael JACOBS ${ }^{* 1}$ \\ Departments of *Pharmacology and \$Biochemistry and Molecular Biology, Royal Free Hospital School of Medicine, Rowland Hill Street, London NW3 2PF, U.K., and \\ †Thrombosis Research Institute, Emanuelle Kaye Building, Manresa Road, London SW3 6LX, U.K.
}

\begin{abstract}
The modification of tyrosine residues in proteins to 3-nitrotyrosine by peroxynitrite or other potential nitrating agents has been detected in biological systems that are subject to oxidative stress. A convenient semi-quantitative method has been developed to assay nitrated proteins in biological fluids and homogenates using a competitive ELISA developed in our laboratory. This assay selectivity detected 3-nitro-L-tyrosine residues in a variety of peroxynitrite-treated proteins (BSA, human serum albumin (HSA), $\alpha_{1}$-antiprotease inhibitor, pepsinogen and fibrinogen) and also in a nitrated peptide, but had a low affinity for free 3-nitro-L-tyrosine and 3-chloro-L-tyrosine. The $\mathrm{IC}_{50}$ values for the inhibition of antibody binding by different nitrated proteins were in the range 5-100 nM, suggesting that the antibody discriminated between nitrotyrosine residues in different environments. The presence of nitrotyrosine in plasma proteins
\end{abstract}

was detected by Western blot analysis and quantified by the ELISA. A concentration of $0.12 \pm 0.01 \mu \mathrm{M}$ nitro-BSA equivalents was measured in the proteins of normal plasma which was increased in peroxynitrite-treated plasma and was elevated in inflammatory conditions. HSA and low-density lipoprotein (LDL) isolated from plasma contained $0.085 \pm 0.04$ and $0.03 \pm 0.006 \mathrm{nmol}$ nitro-BSA equivalents $/ \mathrm{mg}$ protein, respectively. Comparison of the level of nitration in peroxynitritetreated HSA and LDL in the presence and absence of plasma indicates that nitration and presumably oxidation is inhibited by plasma antioxidants. The presence of nitrotyrosine in LDL is consistent with previous reports implicating peroxynitrite in the oxidative modification of lipoproteins and the presence of a low concentration of oxidized LDL in the blood.

\section{INTRODUCTION}

Tyrosine residues in proteins including enzymes are chemically converted by tetranitromethane [1] and peroxynitrite [2-4] to nitrotyrosine. Such modifications may lead to changes in enzyme activity [5]. In biological systems, peroxynitrite is generated from the reaction of superoxide anions with $\mathrm{NO}$, an ubiquitous free radical that is released from a variety of cells including endothelial cells, activated neutrophils and macrophages [2,4]. The latter cells also release these superoxide anions either as a byproduct of normal metabolism or from the oxidative burst following immunological and cytokine activation [4]. Peroxynitrite is a potent and relatively long-lived oxidant that may serve as an important cytotoxic agent particularly in diseases involving cytotoxic damage such as acute lung disease and atherosclerosis [4]. In fact, peroxynitrite has been implicated in the oxidative modification of low-density lipoproteins (LDL) [6] and nitrotyrosine was detected in atherosclerotic plaque [7]. LDL are therefore prime candidates for nitration among the plasma proteins. Although the formation of nitrotyrosine is often attributed to nitration by peroxynitrite, additional mechanisms have been proposed. These involve other reactive nitrogen species including pathways independent of peroxynitrite [8-12]. In addition, the gaseous phase of cigarette smoke has the capacity to convert free tyrosine to 3-nitrotyrosine [13].

It is apparent from the attempt to measure free nitrotyrosine levels in the serum and synovial fluid from healthy volunteers by HPLC [14], that its concentration is below the detectable limit $(0.2 \mu \mathrm{M})$. A much higher concentration of 3-nitrotyrosine has been found by this method in plasma proteins prepared from blood which had been preincubated for $4 \mathrm{~h}$ at $37^{\circ} \mathrm{C}$ [15]; the level in fresh plasma is likely to be considerably lower, but has not been satisfactorily determined. A metabolite of nitrotyrosine has also been detected in human urine using gas chromatography by Oshima et al. [16], suggesting that endogenous nitrotyrosine formation may be part of normal physiological processes.

In order to investigate further the level of nitrotyrosine in human plasma proteins as a potential biomarker for oxidative stress and the putative role of protein nitration in physiological and pathophysiological processes, a competitive enzyme-linked immunosorbent assay (ELISA) for nitrotyrosine has been developed in our laboratory (reported at the Proceedings of the British Pharmacological Society [17]). In this present study, the applicability of this assay to the measurement of nitrotyrosine in a variety of proteins has been examined and nitrotyrosine quantified in plasma proteins including serum albumin and LDL isolated from the blood of healthy subjects.

\section{MATERIALS AND METHODS}

\section{Materials}

Bovine serum albumin (fatty acid free) was obtained from Boehringer Mannheim. Keyhole limpet haemocyanin (KLH) (H7017), fibrinogen (F-4129), pepsinogen (P-4781), $\alpha_{1}$-antiproteinase (A-9024) and human serum albumin (HSA) (fatty acid free, A-1887), L-tyrosine, 3-nitro-L-tyrosine, 3-chloro-L-tyrosine, 4-nitro-L-phenylalanine, $O$-phospho-L-tyrosine, 3-amino-L-tyrosine, Gly-Gly-Tyr-Arg and other reagents (analytical grade) were purchased from Sigma Biochemicals (Poole, Dorset, U.K.).

Abbreviations used: · $\mathrm{NO}$, nitric oxide; $\cdot \mathrm{NO}_{2}$, nitrogen dioxide; nitro-BSA, nitrated BSA; CV, coefficient of variation; HSA, human serum albumin; LDL,

low density lipoproteins; KLH, keyhole limpet haemocyanin; SOD, superoxide dismutase.

1 To whom correspondence should be addressed. 
Biotinylated donkey anti-rabbit $\mathrm{IgG}$ antibodies were obtained from Amersham Life Sciences (U.K.) and avidin and biotinylated horseradish peroxidase from DAKO (Denmark). Amplified alkaline phosphatase immunoblotting kit was purchased from BioRad (Herts, U.K.). Immuno-affinity purified polyclonal antinitrotyrosine rabbit $\mathrm{IgG}$ raised to nitrated $\mathrm{KLH}$ was obtained from TCS Biologicals (Bucks, U.K.)

\section{Preparation of plasma and plasma proteins}

Fasted venous blood samples were obtained from healthy nonsmoking volunteers (age 20-30) and from patients with the inflammatory condition, systemic sclerosis (donated by Professor C. M. Black, Department of Rheumatology, Royal Free Hospital School of Medicine) with informed consent. Plasma was prepared by centrifugation in EDTA-coated tubes and used immediately to prepare LDL as previously described [18] or aliquoted and rapidly frozen for the ELISA. HSA was separated from nonHSA proteins in samples of plasma by affinity chromatography using a column of Affi-Gel blue affinity gel according to the manufacturer's instructions (Bio-Rad, Herts, U.K.). The column was washed with Tris buffer $\mathrm{pH} 7.4$ to remove non-HSA fraction (unbound) and then the HSA was eluted from the column with buffer containing $1.4 \mathrm{M} \mathrm{NaCl}$ and dialysed against PBS to remove salt.

\section{Synthesis of nitrated proteins}

Peroxynitrite was prepared by the published method [19]. Nitrated bovine serum albumin (nitro-BSA; 3-6 mol nitrotyrosine/mol protein), nitrated plasma and other proteins were prepared by three additions of an alkaline stock solution of peroxynitrite to a final concentration of $1 \mathrm{mM}$ [19]. Control experiments were performed using peroxynitrite prepared in $0.5 \mathrm{M}$ phosphate buffer $\mathrm{pH} 7.4$, conditions which resulted in the rapid decomposition of peroxynitrite. Proteins were dialysed against three changes of PBS (2 1) and the 3-nitrotyrosine content of nitro-BSA (and other proteins) was determined by absorbance at $438 \mathrm{~nm}$ at $\mathrm{pH} 9.0$ using a molar extinction coefficient of $4300 \mathrm{M}^{-1} \mathrm{~cm}^{-1}$ [2] and was in the range of 3-6 mol nitrotyrosine $/ \mathrm{mol}$ protein.

\section{ELISA for 3-nitrotyrosine}

Method

3-Nitrotyrosine-modified proteins were quantified by a competitive ELISA developed in our laboratory [17]. The assay was performed in 96-well plates coated with $4 \mu \mathrm{g} / \mathrm{ml}$ nitro-BSA (immobilized antigen) which had been blocked with ovalbumin to prevent non-specific binding. A standard curve was constructed by incubating in the wells serial dilutions of nitro-BSA in PBS with immunoaffinity purified polyclonal anti-nitrotyrosine rabbit IgG $(1: 30000)$ for $2 \mathrm{~h}$ at $37^{\circ} \mathrm{C}$, followed by washing the plate with PBS. Sequential incubations were then performed with biotinylated donkey anti-rabbit IgG and avidin-biotin horseradish peroxidase complex. After further washing, colour development was initiated by the addition of substrate and was allowed to develop for up to $30 \mathrm{~min}$ at room temperature and terminated by the addition of $4 \mathrm{M}$ sulphuric acid. Antibody binding was determined from the absorbance at $490 \mathrm{~nm}$. The competitive inhibition of antibody binding by plasma (up to $1: 5$ dilution) and other agents was performed in triplicate by substituting them for nitro-BSA in the incubation. The concentrations of nitrated proteins that inhibit anti-nitrotyrosine anti- body binding were estimated from the standard curve and are expressed as nitro-BSA equivalents, i.e. an equivalent concentration of 3-nitrotyrosine in nitro-BSA that produces the equivalent inhibition as the nitrated proteins. It was noted that the quantification is only semi-quantitative on mixtures of proteins because their affinity for the antibody may differ from that of nitro-BSA (see below). Data for the standard curves were fitted to a logistic plot and $\mathrm{IC}_{50}$ values calculated using Fig $\mathrm{P}$ software (Elsevier, Cambridge, U.K.).

\section{Precision of the assay}

The nitrotyrosine concentrations of 3-nitrotyrosine measured in serial dilutions of the standard nitro-BSA were accurate to $\pm 10 \%$. Regression coefficients for the standard curve for each assay were $>0.99$. The interassay precision of the concentration of nitrotyrosine in plasma proteins based on four different nonsmoking donors performed in four assays was $9.4 \%$. The percentage coefficient of variation $(\% \mathrm{CV})$ within an assay performed on the same plate was $9.2 \%$. The intra- and interassay precision was comparable to that expected in an ELISA.

\section{SDS/PAGE and Western blotting}

Reduced and denatured plasma samples were subject to SDS/PAGE using $10 \%$ polyacrylamide gels [20]. Bands were transferred to nitrocellulose by semi-dry blotting. Non-specific sites on the nitrocellulose were blocked with milk protein for $16 \mathrm{~h}$ at $4{ }^{\circ} \mathrm{C}$ and then overlaid with polyclonal anti-nitrotyrosine rabbit antibody, followed by biotinylated goat anti-rabbit IgG plus biotinylated alkaline phosphatase complexed with streptavidin. Controls were performed by preincubating the antinitrotyrosine antibody with nitro-BSA, using the secondary antibody alone or treating the blot with $10 \mathrm{mM}$ dithionite [20].

\section{Statistical analysis}

Data were expressed as mean \pm S.E.M. where $n$ is the number of different experiments or plasma samples. Statistical analysis was performed using InStat computer software (GraphPad Inc.) using Mann-Whitney non-parametric test for unpaired samples with $P<0.05$ considered significant.

\section{RESULTS}

\section{The detection of nitrotyrosine by ELISA}

\section{Selectivity of the assay}

A new assay was developed, a competitive ELISA which was optimized to quantify protein nitration (3-nitrotyrosine residues in proteins). Standard curves were constructed by determining the inhibition of the binding of the anti-nitrotyrosine antibody to the immobilized antigen in the presence of serial dilutions of free nitro-BSA or 3-nitrotyrosine. Figure 1 shows that the standard curves for nitrotyrosine in nitro-BSA and free nitrotyrosine were linear over a range of $3.8-900 \mathrm{nM}$ and $10 \mu \mathrm{M}-10 \mathrm{mM}$ nitrotyrosine, respectively. The $\mathrm{IC}_{50}$ for $\mathrm{BSA}$ was $16.7 \pm 0.7 \mathrm{nM}$ $(n=4)$ and a similar value was obtained for HSA $(16.6 \pm 1.2 \mathrm{nM}$, $n=4 ; P>0.05)$. This compares with the $\mathrm{IC}_{50}$ value of $300 \pm 92 \mu \mathrm{M}(n=4)$ for free nitrotyrosine, showing that antibody has a higher affinity for nitrotyrosine residues in proteins than for the free amino acid. In contrast, chlorotyrosine (Figure 1) had a $\mathrm{IC}_{50}$ of $59 \pm 1 \mathrm{mM}(n=3)$, which was approx. 200-fold greater than for nitrotyrosine. The peptide, gly-gly-nitrotyrosinearginine also competed with the immobilized antigen $\left(\mathrm{IC}_{50}\right.$, $1.4 \pm 0.04 \mu \mathrm{M}, n=4$ ) but had lower affinity for the antibody 


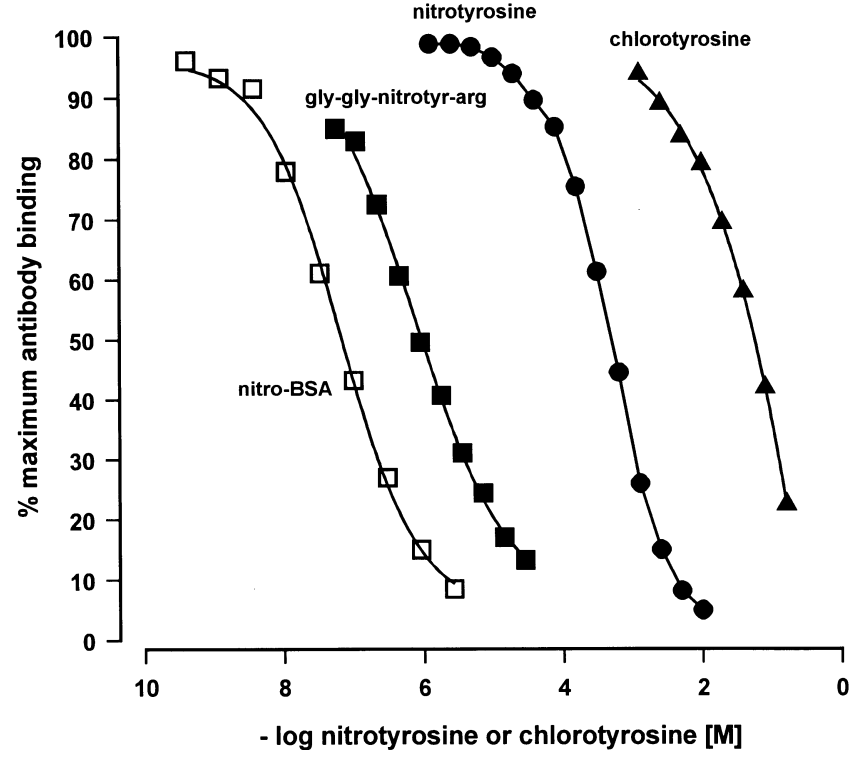

Figure 1 Comparison of the standard curves for the inhibition of antinitrotyrosine antibody binding by various antigens in the competitive ELISA

The curves show the competition for the anti-nitrotyrosine antibody between the immobilized nitro-BSA and competing free antigens: nitro-BSA ( $n=12$ experiments), gly-gly-nitrotyr-arg ( $n$ $=4)$, free 3-nitro-L-tyrosine $(n=4)$ and 3-chloro-L-tyrosine $(n=4)$. \% inhibition of maximum antibody binding (maximum absorbance at $490 \mathrm{~nm}$ in the absence of competition) is plotted against the nitrotyrosine or chlorotyrosine concentration in the competing antigen.

Table 1 The specificity of anti-nitrotyrosine antibody binding to nitrated serum albumin coated plates

The antibody is incubated with various substances and binding determined using the ELISA assay as described in Materials and Methods. Results are expressed as mean \pm S.E.M. of four experiments.

\begin{tabular}{clc}
\hline Concentration & Inhibitor & $\begin{array}{c}\text { \% Inhibition of } \\
\text { antibody binding }\end{array}$ \\
\hline $10 \mathrm{mM}$ & Nitrotyrosine & $95.8 \pm 0.4$ \\
$10 \mathrm{mM}$ & Tyrosine & $3.3 \pm 0.4$ \\
$10 \mathrm{mM}$ & Phenylalanine & $1.0 \pm 0.7$ \\
$10 \mathrm{mM}$ & Nitrophenylalanine & $4.9 \pm 2.1$ \\
$10 \mathrm{mM}$ & Aminotyrosine & $0.2 \pm 0.2$ \\
$10 \mathrm{mM}$ & Phosphotyrosine & $1.9 \pm 0.7$ \\
$10 \mathrm{mM}$ & Methionine & 0.0 \\
& PN-methionine & 0.0 \\
$10 \mathrm{mM}$ & Tryptophan (con-PN) & $6.5 \pm 1.0$ \\
& PN-tryptophan & 0.0 \\
$10 \mathrm{mM}$ & Cysteine (con-PN) & 0.0 \\
& PN-cysteine & 0.0 \\
$758 \mathrm{nM}$ & Nitro-BSA & $86.5 \pm 0.65$ \\
$758 \mathrm{nM}$ & BSA & $0.3 \pm 0.2$ \\
$0.74 \mathrm{mM}$ & BSA & $22.6 \pm 1.9$ \\
$714 \mathrm{nM}$ & KLH & $2.5 \pm 1.2$ \\
$10 \mathrm{mM}$ & Sodium nitrite & $7.0 \pm 1.0$ \\
$10 \mathrm{mM}$ & Sodium nitrate & $5.1 \pm 1.2$ \\
& & \\
\hline
\end{tabular}

than nitro-BSA. The assay was highly specific for 3-nitrotyrosine residues as shown by competition experiments with other amino acids and unmodified proteins (Table 1). Antibody binding was blocked by $10 \mathrm{mM}$ nitrotyrosine and by nitro-BSA. The inhibition of the antibody by $10 \mathrm{mM}$ tyrosine, phenylalanine, $O$ -

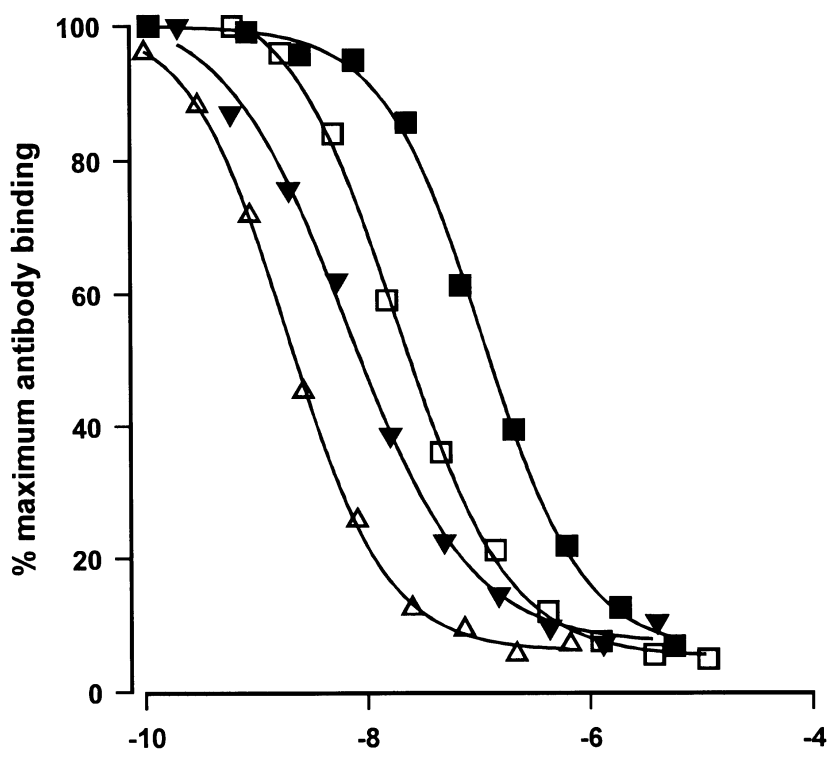

- log protein-nitrotyrosine concentration [M]

Figure 2 Competition for anti-nitrotyrosine antibody binding in the ELISA by a variety of proteins

The curves are representive of four independent experiments for each nitrated protein: $\triangle, \mathrm{KLH}$; $\boldsymbol{\nabla}$, fibrinogen; $\square$, pepsinogen; $\mathbf{Q}, \alpha_{1}$-antiproteinase. Curves were constructed as described in Figure 1. $I C_{50}$ values are given in Table 2. Proteins were nitrated as described in Materials and Methods.

phosphotyrosine, 3-aminotyrosine, 4-nitrophenylalanine, nitrite and nitrate were not significant as they were below that corresponding to the lowest detectable concentration of nitrotyrosine $(8.3 \pm 1.3 \%, n=4)$. Peroxynitrite-treated cysteine, methionine and tryptophan had no significant influence on antibody binding and was comparable to the inhibition found when these amino acids were treated with decomposed peroxynitrite. In proteins, these latter amino acids are likely to undergo oxidation by peroxynitrite [21] and in addition nitrotryptophan may be formed [22]. Unmodified BSA (758 nM) or KLH $(714 \mathrm{nM})$, the antigen to which the anti-nitrotyrosine antibody was raised, showed no significant cross reaction. At higher concentration $(0.74 \mathrm{mM})$ comparable with that in plasma, unmodified HSA and BSA cross-reacted to a small extent due to their endogenous nitration (see below).

\section{Detection of nitrotyrosine residues in different proteins and enzymes}

The validity of the ELISA for use with a range of other proteins was investigated. A variety of commercially available proteins were nitrated in vitro: KLH, fibrinogen, pepsinogen, $\alpha$-antiproteinase. Their nitration was determined by absorbance measurements and standard curves were constructed using serial dilutions of these proteins which competed with the immobilized nitro-BSA for the anti-nitrotyrosine antibody (Figure 2). The nitrated proteins had different affinities for the antibody in the order: $\mathrm{KLH}>$ fibrinogen $>$ pepsinogen $>\alpha_{1}$-antiproteinase (Table 2). Prior to nitration, the nitrotyrosine present in these proteins was undetectable by the ELISA except for $2.2 \pm 0.14$ pmol nitro-BSA equivalents/mg protein $(n=4)$ in fibrinogen. 
Table 2 IC $_{50}$ values for the inhibition of anti-nitrotyrosine antibody binding by various proteins

The following proteins were nitrated in vitro: KLH, fibrinogen, pepsinogen, $\alpha_{1}$-antiproteinase. $\mathrm{IC}_{50}$ are estimated from the curves shown in Figure 2 and are expressed as mean \pm S.E.M. $(n=4)$.

\begin{tabular}{|c|c|}
\hline Proteins & $\mathrm{IC}_{50} \mathrm{nM}$ \\
\hline $\mathrm{KLH}$ & $5.2 \pm 1.8$ \\
\hline Fibrinogen & $9.6 \pm 2.2$ \\
\hline Pepsinogen & $48.3 \pm 14.9$ \\
\hline$\alpha_{1}$-Antiproteinase & $100 \pm 15.4$ \\
\hline
\end{tabular}

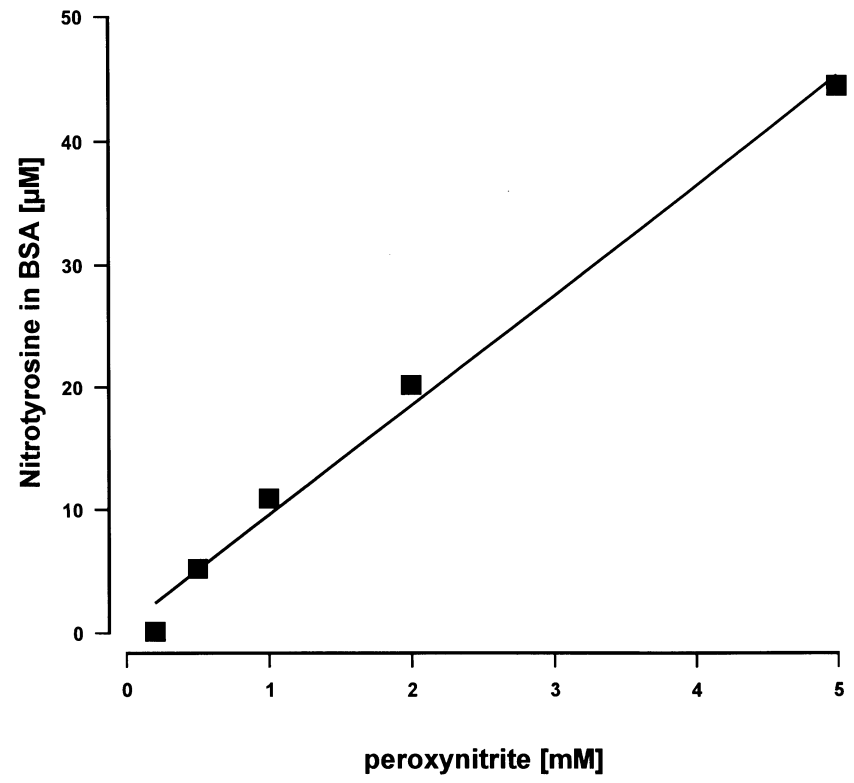

Figure 3 Nitrotyrosine in BSA nitrated with varying peroxynitrite concentrations

One addition of peroxynitrite was added to $\mathrm{BSA}(30 \mu \mathrm{M})$ to give final concentrations of $0.2-5 \mathrm{mM}$. After dialysis of the protein, the nitrotyrosine was determined by ELISA. The data show a linear relationship between peroxynitrite concentration and the concentration of nitrotyrosine equivalents in BSA.

\section{Influence of peroxynitrite concentration on protein nitration}

Experiments were performed to see whether the nitration of BSA in vitro as quantified by the ELISA as nitrotyrosine equivalents in BSA, correlated with the peroxynitrite concentration. BSA was exposed to different concentrations of peroxynitrite to produce nitro-BSA containing 1-6 mol nitrotyrosine/mol protein. Figure 3 shows that there is a linear correlation between the peroxynitrite concentration used in the nitration reaction and the nitrotyrosine content of the nitro-BSA that is produced. The nitrotyrosine content of BSA was in agreement with that measured by HPLC (not shown).

\section{The influence of plasma on the standard curve for nitro-BSA}

It was important to determine that nitrotyrosine residues were stable in the presence of plasma as estimated by the ELISA. Standard curves were constructed with serial dilutions of nitroBSA in the presence or absence of plasma (1:10 dilution) or after

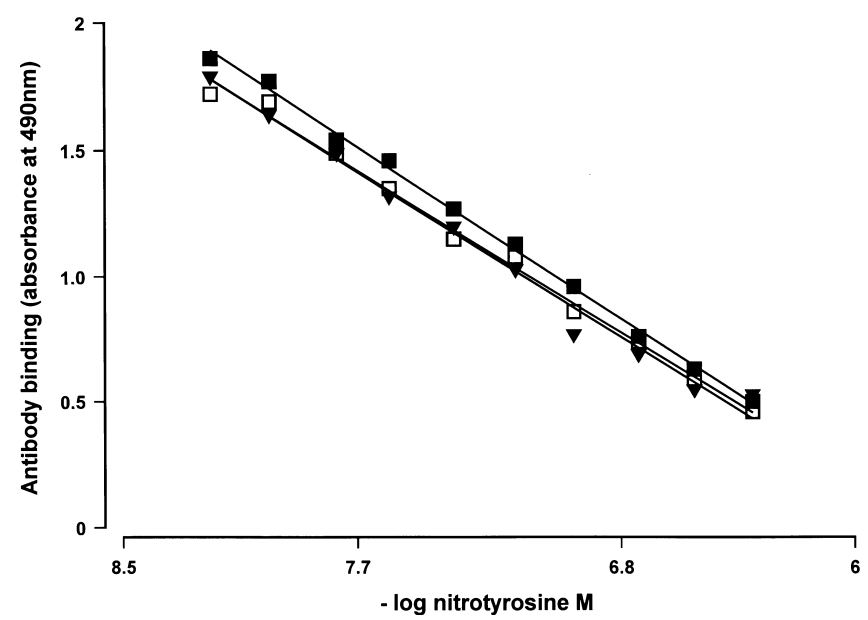

Figure 4 The influence of plasma on the standard curve for nitro-BSA

Measurements of antibody binding (absorbance) were performed by ELISA on mixtures of nitroBSA with buffer $(10 ; 1 \mathrm{v} / \mathrm{v}), \boldsymbol{\square}$; with plasma $(10: 1 \mathrm{v} / \mathrm{v}), \boldsymbol{\nabla}$; with plasma $(10: 1 \mathrm{v} / \mathrm{v})$ after preincubation for $1 \mathrm{~h} \square$. Standard curves were constructed as described in Figure 1 (only the linear portion of the curves are shown). The curves are representative of four independent experiments.

Table 3 The detection of nitrated protein in HSA and LDL isolated from peroxynitrite-treated and untreated plasma

HSA and LDL were isolated from the untreated or peroxynitrite pretreated plasma (PN-treated plasma) and their nitration was compared to that in HSA and purified LDL which had been nitrated by peroxynitrite in vitro (PN-treated purified proteins). HSA and LDL were prepared and nitrated as described in Materials and Methods. Nitration (nitro-BSA equivalents/mg protein) was determined by ELISA and is shown as mean \pm S.E.M. of four different experiments.

Plasma proteins

(nitro-BSA equivalents $\mathrm{nmol} / \mathrm{mg}$ protein)

Source of protein

HSA

LDL
PN-treated purified protein

PN-treated plasma

Native plasma
$13.4 \pm 0.9$
$0.87 \pm 0.27$
$0.085 \pm 0.04$
$6.4+2.34$

$0.063 \pm 0.020$

$0.03 \pm 0.006$ preincubation with plasma for $1 \mathrm{~h}$ at room temperature. In the presence of plasma, the standard curve showed a small downward shift in the inhibition of antibody binding (Figure 4) due to the presence of the endogenous nitrotyrosine residues in plasma proteins (see below) but otherwise did not significantly differ from that of nitro-BSA which had been preincubated with buffer or not preincubated. Thus preincubation of plasma with nitroBSA for $1 \mathrm{~h}$ and a further $2 \mathrm{~h}$ during the ELISA had no influence on the inhibition.

\section{3-Nitrotyrosine in plasma proteins}

(a) Total plasma proteins

The concentration of nitrated proteins in plasma samples from healthy non-smoking volunteers was quantified by ELISA. A concentration of $0.12 \pm 0.02 \mu \mathrm{M}$ nitro-BSA equivalents $(n=4)$ in plasma proteins was estimated from the standard curve. The ELISA was also applied to the measurement of nitrated protein in patients with the inflammatory disease Systemic Sclerosis. 
This is an autoimmune connective tissue disorder, characterized by microvascular damage and excessive matrix production [23]. The concentration of nitrated protein was increased by $244 \pm 4 \%$ $(P<0.002 ; n=20)$ in this disease compared to that in the plasma of normal volunteers.

Treatment of normal plasma samples with peroxynitrite in vitro (see Materials and Methods) increased the nitrated protein concentration to $9.1 \pm 2.1 \mu \mathrm{M}$ nitro-BSA equivalents $(n=4$, $P>0.001)$. Control measurements of nitrated protein in plasma which had been treated with peroxynitrite that had been allowed to decompose at neutral $\mathrm{pH}$ for $5 \mathrm{~min}$ were not significantly different from untreated plasma.

The concentration of free nitrotyrosine was determined after deproteinization of normal plasma by ultrafiltration through an Amicon membrane (molecular weight cut-off of $3 \mathrm{kDa}$ ) and was below the detectable limit of $10 \mu \mathrm{M}$.

\section{(b) HSA isolated from normal plasma}

HSA (bound fraction) was purified from fresh plasma and peroxynitrite-treated plasma by chromatography on Affi-Gel blue affinity gel column. The endogenous nitrotyrosine in HSA, quantified by the ELISA is shown in Table 3. In untreated plasma, there was $85 \pm 4$ pmol nitro-BSA equivalents $/ \mathrm{mg}(n=$ 4). This compares with $0.58 \pm 0.04 \mathrm{pmol} / \mathrm{mg}(n=4)$ in unmodified commercial HSA. The HSA contained $56.4 \pm 5.7 \%$ $(n=4)$ of the total nitro-BSA equivalents recovered from the column. The level of nitration of HSA that was isolated from peroxynitrite-treated plasma (Table 3), was increased 10-fold over the level in HSA from untreated plasma $(P<0.03)$. This value was $6.5 \%(P<0.05)$ of that in commercial HSA which had been nitrated in vitro under standard conditions.

\section{(c) Nitrotyrosine in LDL}

Since nitrotyrosine has been detected in atherosclerotic plaques [7], the possibility that plasma LDL might be nitrated was investigated. Native LDL were purified from fresh plasma samples and from samples of plasma that had been nitrated in vitro prior to isolation. Purified LDL were also nitrated under standard conditions (see Materials and Methods) to ascertain the optimal nitration in vitro. The nitration of these various preparations, measured by ELISA is shown in Table 3. The endogenous nitration in native LDL isolated from untreated plasma was $0.05 \%$ of that in purified LDL nitrated in vitro by peroxynitrite and $47.6 \%$ of that in LDL which had been isolated from peroxynitrite-treated plasma.

\section{(d) The detection of nitrated plasma proteins by Western blotting}

The nitration of plasma proteins was confirmed by SDS/ PAGE/immunoblotting of untreated plasma samples from volunteers. Figure 5 shows an example of an immunoblot with the anti-nitrotyrosine antibody of a representative plasma sample compared to nitro-BSA and peroxynitrite-treated plasma proteins. The major protein bands stained by the antibody have molecular masses of 30 and $68 \mathrm{kDa}$. The latter protein comigrated with serum albumin and was stained with an anti-BSA IgG. In addition, other faintly staining bands of molecular mass: $164,141,116,100,76,63,58,46,43,30$ and $<26 \mathrm{kDa}$ were just visible in the untreated plasma on the nitrocellulose blot (not all visible in the photograph). These latter bands were greatly enhanced in the peroxynitrite-treated plasma. After pre-incubation of the anti-nitrotyrosine antibody with nitro-BSA, only very faint staining was visible in both peroxynitrite-treated and untreated plasma as well as nitro-BSA. Similarly, the antibody

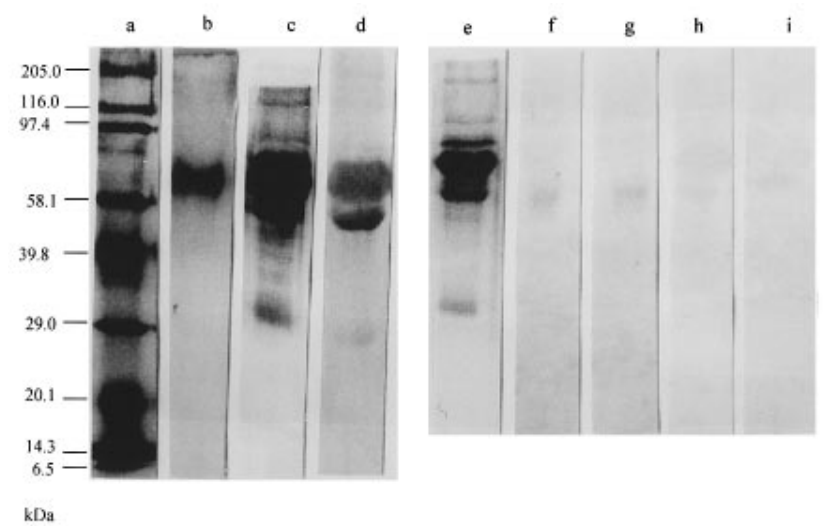

Figure 5 Nitrated proteins in human plasma visualized by immunoblotting

Nitrated proteins were detected in peroxynitrite-treated and untreated plasma by immunoblotting. Slot (a) biotinylated molecular weight markers; (b) nitro-BSA, $0.04 \mu \mathrm{g}$; (c) peroxynitrite-treated plasma, $10 \mu \mathrm{g}$; (d) untreated plasma, $10 \mu \mathrm{g}$; (e) peroxynitrite-treated plasma, $5 \mu \mathrm{g}$; controls : (f) peroxynitrite-treated plasma, $10 \mu \mathrm{g}$; (g) untreated plasma, $10 \mu \mathrm{g}$; (h) peroxynitrite-treated plasma, $10 \mu \mathrm{g}$; and (i) untreated-plasma, $10 \mu \mathrm{g}$. Immunoblotting was performed as described in Materials and Methods. Control blots were incubated with anti-nitrotyrosine antibody plus $1.5 \mathrm{mg} / \mathrm{ml}$ nitro-BSA ( $f$ and $\mathrm{g}$ ) or with $2 \mathrm{mM}$ dithionite (h and i) [18]. Nitro-BSA contained $3 \mathrm{~mol}$ nitrotyrosine/mol protein.

staining was reduced by incubation of the blots with dithionite $(10 \mathrm{mM})$, which reduces nitrotyrosine to non-immunogenic aminotyrosine.

\section{DISCUSSION}

This study describes a competitive ELISA that is specific for the detection of nitrotyrosine residues in proteins and peptides. Other amino acids including $O$-phosphotyrosine and 4-nitrophenylalanine, which have nitrotyrosine-like structures, showed no cross-reaction with the anti-nitrotyrosine antibody (Table 1). This was also the case for other amino acid modifications that are likely to arise through reactions with peroxynitrite, namely oxidation products of cysteine, methionine [21] and oxidized/ nitrated tryptophan [22]. Chlorotyrosine, which may arise in inflammatory situations from neutrophil activation [12], has two orders of magnitude lower affinity for the anti-nitrotyrosine antibody than free nitrotyrosine (Figure 1). The antibody is therefore unlikely to cross-react with chlorotyrosine containing epitopes in normal or inflammatory conditions.

The ELISA was able to detect the nitration of the peptide, glygly-nitrotyrosine-arg and a diverse range of proteins (Figures 1 and 2). These had different affinities for the nitrotyrosine antibody (Table 2), suggesting that antibody binding was influenced by the amino acids adjacent to the nitrotyrosine residues. This ability of anti-nitrotyrosine antibodies to discriminate between nitrotyrosine residues in different environments in proteins may be useful in producing antibodies to specific motifs containing tyrosine residues, e.g. at the active site of enzymes [5] and at tyrosine phosphorylation sites.

The ELISA for nitrated proteins is a sensitive method for determining the relative amounts of nitrated proteins in biological fluids, which will be particularly useful for the measurement of large numbers of unprocessed samples. It is essentially a semiquantitative method with mixtures of proteins since the specific antibody may not bind to all the nitrotyrosine residues in a sample either as a result of lack of access to them or the fact that antibody binding may be influenced by the environment of the 
nitrotyrosine residues (see above). However, analytical techniques for measuring nitrotyrosine such as HPLC and GC/MS have the disadvantage that the samples have to undergo extensive and lengthy processing which can give rise to artifacts. For example, in the presence of contaminating nitrite, acid hydrolysis to release free nitrotyrosine or even mild acid treatment, may result in artifactual nitration and the overestimation of the nitrotyrosine content [24].

The concentration of nitrotyrosine in the untreated plasma of healthy subjects has been quantified for the first time in plasma proteins by an ELISA (see above). The presence of low levels of nitrated proteins in plasma was confirmed by Western blotting and by the detection of nitrotyrosine in HSA and LDL prepared from plasma by affinity chromatography and ultracentrifugation respectively. HSA (molecular weight, $66 \mathrm{kDa} / 18$ tyrosine residues) isolated from native plasma contained an estimated one nitrotyrosine per $3 \times 10^{7}$ tyrosine residues as quantified by ELISA, assuming that all nitrotyrosine residues are detected (Table 3). Assuming that HSA is typical of total plasma proteins, this stoichiometry is of the same order of magnitude as detected in the study by Shigenaga et al. [24] in which nitrite/nitrate contamination was minimized and enzymatic hydrolysis was used. This is considerably lower than previous measurements [15] where no precautions were taken against artifactual nitration. The antioxidants in plasma appear to offer HSA some protection against nitration by peroxynitrite since the level of nitration of the purified protein in vitro in the absence of plasma is considerably higher than when HSA was isolated from peroxynitritetreated plasma (Table 3 ).

In spite of one report suggesting that protein-nitrotyrosine is degraded by plasma [25], no evidence was found for this using the competitive ELISA (Figure 4). In addition, it was unlikely that nitrotyrosine was lost during the assay, as similar amounts of nitrated proteins were recovered from plasma after TCA precipitation, a treatment which was likely to have inactivated any enzyme that might have degraded nitrotyrosine residues (J. Khan et al. unpublished work).

The nitration found in HSA isolated from untreated plasma was considerably lower than in commercial HSA (see above), but was similar to the value found by Oshima et al. (0.4 pmol $/ \mathrm{mg})$, in commercially available proteins [16]. This low nitrotyrosine content compared with that found in HSA from untreated plasma suggests that nitrotyrosine-modified protein has been lost during commercial preparation, for example, by exposure to reducing agents. Alternatively, a proportion of the nitrotyrosinecontaining proteins may be in the form of immune complexes (J. Khan et al. unpublished work) which are lost from the bulk of the unmodified HSA during preparation.

Endogenous nitrotyrosine residues were detected in LDL of normal plasma (Table 3). This observation is consistent with the presence of low concentrations of lipid peroxides in plasma LDL [26], implying that plasma proteins including lipoproteins are constantly exposed to low levels of oxidants, including peroxynitrite. The endogenous nitration of LDL could arise from the antioxidant action of $\mathrm{NO}$ in causing chain termination in peroxidation reactions [27]. Products of this reaction in LDL will be organic peroxynitrites which could be scavenged locally by a reaction with the tyrosyl groups in apolipoprotein $\mathrm{B}$, giving rise to the endogenous nitrotyrosine. It is also possible that NO might be targeted to lipoproteins because of its hydrophobicity and so facilitate the nitration reaction. It is also notable that the endogenous nitration of LDL is about half that of the lipoproteins isolated from peroxynitrite-treated plasma but is considerably less than the purified LDL nitrated with peroxynitrite in vitro (Table 3). This implies that apolipoprotein B in LDL is protected against nitration, and presumably oxidation, by plasma antioxidants as well as the endogenous antioxidants in lipoproteins. Possible plasma antioxidants include ascorbic acid and thiols which are both known to be inhibitors of peroxynitrite-induced oxidation [4]. In hypercholesterolaemia, the accumulation of LDL in the vessel wall where these antioxidants may be absent, would promote peroxynitrite-induced modification of lipoproteins. It is likely that peroxynitrite contributes to this oxidation since in vitro experiments have shown that peroxynitrite oxidizes LDL [6] and causes oxidative modification in vivo as indicated by the detection of nitrotyrosine in atherosclerotic plaque [7].

The level of nitrated protein in fresh normal plasma, found in this study was considerably lower than achieved by nitration of plasma proteins in vitro by peroxynitrite (Table 3 ). This suggests that elevated levels of nitrotyrosine-modified plasma proteins will be found in diseases involving oxidative damage in which higher concentrations of nitric oxide and superoxide anions might be expected as has been previously shown in tissues from patients with acute lung injury [28] and atherosclerosis [7] by immunohistochemical staining using anti-nitrotyrosine antibody. This was confirmed by the finding of elevated concentrations of nitrated proteins in the plasma from patients with the inflammatory disease, systemic sclerosis. A study using a kit developed from our ELISA method (TCS Biologicals) has also demonstrated elevated levels of nitration in the bronchial lavages from children with severe respiratory syncytial virus infection [29]. Preliminary studies in our laboratory using the ELISA have detected concentrations of nitrated protein in the bronchial lavages of patients with adult respiratory distress syndrome between two- and 100-fold greater than in the lavages of normal subjects, comparable to the increases found by HPLC (J. Khan and G. J. Quinlan, unpublished work). Furthermore, nitrated proteins have also been detected in synovial fluid and ovarian follicular fluid as well as in platelet homogenates treated with peroxynitrite (J. Khan, unpublished work).

Peroxynitrite is synthesized from the reaction of superoxide anions with NO produced by nitric oxide synthase and is the most likely reactive nitrogen species to modify the tyrosine residues of plasma proteins to nitrotyrosine [4]. Superoxide will be generated as result of the exposure of cells to oxidative stress due to low level infections or to normal catabolic and metabolic processes (e.g. by autoxidation of ascorbic acid, catecholamines, thiols etc.). It is also notable that superoxide anions react with nitric oxide more rapidly than it is dismutated and the tyrosine to nitrotyrosine conversion is catalysed by the metal centres of superoxide dismutase [2,4]. It has been pointed out by Beckman et al. [4] that intracellularly, peroxynitrite formation will be favoured over dismutation by (SOD) superoxide dismutase. A scenario can be envisaged under normal physiological conditions in which the stable cis-form of peroxynitrite generated intracellularly is targeted by EC-SOD to nitrate plasma proteins at the surface of the endothelium. Although peroxynitrite like NO is inactivated by haemoglobin in the plasma compartment, a nitration scavenger pathway for peroxynitrite could contribute to its inactivation or fulfil some unknown physiological function. Peroxynitrite may not be the only source of nitration. Additional or alternative nitrating agents have been suggested, such as the reactive nitrogen species, $\cdot \mathrm{NO}$ or $\cdot \mathrm{NO}_{2}$ [8-11] or the myeloperoxidase-dependent oxidation of nitrite by neutrophils [10-12]. It should also be recognized that nitrated protein will accumulate over the life-time of the plasma proteins and will reflect the exposure of these proteins to peroxynitrite and other putative nitrating agent generated, for example as part of any inflammatory response or other events in which oxidative stress is implicated. 
Irrespective of the nitrating agent, the presence of nitrated proteins in normal plasma implies either that the modification occurs within the circulation or that the proteins are exported in this form from cells, e.g. undergoing apoptosis, or in the extracellular space. Furthermore, nitrotyrosine residues in proteins may arise by post-translational modification or alternatively by the nitration of free tyrosine and subsequent incorporation into proteins during transcription. Either way the nitration pathway represents a novel mechanism that has implications for normal physiological functions such as in signal transduction [30], the regulation of enzyme activity [5] and possibly apoptosis [31].

We thank the British Heart Foundation and the Peter Samuel Royal Free Fund for their support.

\section{REFERENCES}

1 Sokolovsky, M., Riordan, J. F. and Vallee, B. L. (1966) Biochemistry 5, 3582-3589

2 Ischiropoulos, H., Zhu, L., Chen, J., Tsai, M., Martin, J. C., Smith, C. D. and Beckman, J. S. (1992) Archiv. Biochem. Biophys. 298, 431-437

3 Ischiropoulos, H. and Al-Mehdi, A. B. (1995) FEBS Lett. 364, 279-282

4 Beckman, J. S. and Koppenol, W. H. (1996) Am. J. Physiol. 271, C1424-C1437

5 Richards, P. G., Walton, D. J. and Heptinsall, J. (1996) Biochem. J. 315, 473-479

6 Graham, A., Hogg, N. A., Kalyanaraman, O'Leary, V. J., Darley-Usmar, V. M. and Moncada, S. (1993) FEBS Lett. 330, 181-185

7 Beckman, J. S., Ye, Y. Z., Anderson, P. G., Chen, J., Accavitti, M. A., Tarpey, M. M. and White, C. R. (1994) Biol. Hoppe-Seyler 375, 81-88

8 Van der Vliet, A., Eiserich, J. P., O'Neill, C. A., Halliwell, B. and Cross, C. (1995) Archiv. Biochem. \& Biophys. 319, 341-349

9 Eiserich, J. P., Butler, J., Van der Vliet, A., Cross, C. E. and Halliwell, B. (1995) Biochem. J. 310, 745-749

10 Eiserich, J. P., Cross, C. E., Jones, A. D., Halliwell, B. and Van der Vliet, A. (1996) J. Biol. Chem. 271, 19199-19208

11 Halliwell, B. (1997) FEBS Lett. 411, 157-160
12 Van der Vliet, A., Eiserich, J. P., Halliwell, B. and Cross, C. (1997) J. Biol. Chem. 272, 7617-7625

13 Eiserich, J. P., Vossen, V., O'Neill, C. A., Halliwell, B., Cross, C. E. and Van der Vliet, A. (1994) FEBS Lett. 353, 53-56

14 Kaur, H. and Halliwell, B. (1994) FEBS Lett. 350, 9-12

15 Salman-Tabcheh, S., Guerin, M. C. and Torreilles, J. (1995) Free Radical Biol. Med. 19, 695-698

16 Oshima, H., Friesen, M., Brouet, I. and Bartsch, H. (1990) Food Chem. Toxicol. 28, 647-652

17 Khan, J., Brennan, D. M., Bruckdorfer, K. R. and Jacobs, M. (1995) Br. J. Pharmacol. 116, 328P

18 Jacobs, M., Plane, F. and Bruckdorfer, K. R. (1990) Br. J. Pharmacol. 100, 21-26

19 Beckman, J. S., Chen, J. S., Ischiropoulos, H. and Crow, J. P. (1994) Methods in Enzymol. 233, 229-240

20 Haddad, I. Y., Crow, J. P., Hu, P., Yaozu, Y., Beckman, J. and Matalon (1994) Am. J. Physiol. 267, L242-L249

21 Pryor, W. A. and Stone, K. (1993) Ann. New York Acad. Sci. 686, 12-28

22 Padmaja, S., Ramazenian, M. S., Bounds, P. L. and Koppenol, W. H. (1996) Redox Rep. 2, 173-177

23 Black, C. M. (1993) J. Int. Med. 234, 3-8

24 Shigenaga, M. K., Lee, H. H., Blount, B. C., Christen, S., Shigeno, E. T., Yip, H. and Ames, B. N. (1997) Proc. Natl. Acad. Sci. 94, 3211-3216

25 Gow, A. J., Duran, D., Malcolm, S. and Ischiropoulos, H. (1996) FEBS Lett. 385, 63-66

26 Nourooz-Zadeh, J., Tajaddini-Sarmadi, J., Ling, E. and Wolff, S. (1996) Biochem. J. 313, 781-786

27 Rubbo, H., Radi, R., Trujillo, M., Telleri, R., Kalyanaraman, B., Barnes, S., Kirk, M. and Freeman, B. A. (1994) J. Biol. Chem. 269, 26066-26075

28 Haddad, I. Y., Pataki, G., Hu, P., Galliani, C., Beckman, J. S. and Matalon, S. (1994) J. Clin. Inv. 94, 2407-2413

29 Kerr, M. H. (1997) in an Investigation of the Pulmonary Surfactact System in Children with Severe Respiratory Syncytial Virus Infection. Ph.D. thesis accepted by Faculty of Medicine, University of Glasgow

30 Elliot, S. (1996) Am. J. Physiol. 270, L954-L961

31 Lin, K. T., Xue, J. Y., Nomen, M., Spur, B. and Wong, P. Y. K. (1995) J. Biol. Chem. 270, $16487-16490$

Received 23 May 1997/22 October 1997; accepted 7 November 1997 